\title{
Autour de la céramique médiévale. Projets de recherche en cours
}

\section{Fabienne Ravoire}

\section{(2) OpenEdition}

1 Journals

Édition électronique

URL : https://journals.openedition.org/cem/767

DOI : $10.4000 / \mathrm{cem} .767$

ISSN : 1954-3093

Éditeur

Centre d'études médiévales Saint-Germain d'Auxerre

Édition imprimée

Date de publication : 15 août 2005

ISSN : 1623-5770

Référence électronique

Fabienne Ravoire, "Autour de la céramique médiévale. Projets de recherche en cours », Bulletin du centre d'études médiévales d'Auxerre / BUCEMA [En ligne], 9 | 2005, mis en ligne le 03 novembre 2006, consulté le 22 septembre 2022. URL : http://journals.openedition.org/cem/767 ; DOI : https://doi.org/ 10.4000/cem.767

Ce document a été généré automatiquement le 22 septembre 2022.

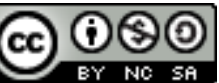

Creative Commons - Attribution - Pas d'Utilisation Commerciale - Partage dans les Mêmes Conditions 4.0 International - CC BY-NC-SA 4.0

https://creativecommons.org/licenses/by-nc-sa/4.0/ 


\title{
Autour de la céramique médiévale. Projets de recherche en cours
}

\author{
Fabienne Ravoire
}

1 Plusieurs projets sont en cours et concernent deux aspects de l'étude de la céramique médiévale qui nous paraissent essentiels :

2 - le premier thème de recherche est tout à fait inhérent à l'étude de sites artisanaux car il concerne l'implantation des ateliers et la diffusion de leurs productions ;

3 - le second thème est plus centré sur l'histoire sociale et culturelle puisqu'il vise à replacer l'objet céramique dans sa relation avec les utilisateurs.

I. La céramique médiévale et moderne dans le quart nord-ouest du Bassin parisien (XII ${ }^{\mathrm{e}}$ XVIII siècle) (île-de-France-Bourgogne)

4 Le champ d'intervention est large dans la mesure où il prend en compte les données archéologiques issues de contextes urbains et ruraux de nature variée en les associant, quand cela est possible, avec les sources historiques. La fourchette chronologique concernée est étendue, du XII ${ }^{e}$ au XVIII ${ }^{e}$ siècle, avec cependant un intérêt particulier pour la période comprenant la fin du Moyen Âge et la Renaissance. La zone géographique de référence est l'ouest du Bassin parisien.

A. Les centres de productions et leur diffusionL'artisanat céramique à Paris

5 Caractérisation pétrographique

6 Dans le cadre du programme de recherches entamé avec le "Centre de recherche et de restauration des musées de France" sur les productions de Bernard Palissy à Paris (cf. ci-dessous), et à la suite de l'étude sur les productions régionales à partir de la typochronologie du mobilier archéologique ${ }^{1}$. la caractérisation des productions céramiques d'Île-de-France de la fin du Moyen Âge et de la Renaissance a été traitée de manière spécifique. Les centres de productions régionaux et leur diffusion ont d'abord été étudiés à partir des méthodes physico-chimiques ${ }^{2}$. Le travail se poursuit, avec la collaboration d'Anne Bouquillon (C2RMF), autour des analyses pétrographiques, dont les nouvelles données permettront de compléter la cartographie existante ${ }^{3}$.

7 Localisation géographique (SIG) 
Ce projet s'inscrit dans le cadre du PCR “Cartographie de l'espace parisien" engagé pour trois ans depuis mars 2005 et dirigé par Claire Besson et Dorothée Derrieux (conservateurs du patrimoine au Service régional d'île-de-France). Il fédère des historiens, archéologues, archivistes, environnementalistes qui sont amenés à travailler sur le territoire parisien, afin de partager les ressources, confronter les données et obtenir à terme un système d'information géographique (SIG) sur la topographie historique de Paris ${ }^{4}$. Notre objectif, dans ce cadre, est l'étude de l'évolution sur la longue durée, d'un point de vue spatial, et dans une perspective historique de l'artisanat céramique à Paris.

Constitution d'une base de données de références

10 Un important travail d'inventaire des productions de la fin du Moyen Âge a eu lieu dans le cadre de notre doctorat qui portait sur "La vaisselle de terre cuite en Île-de-France entre la fin du XVe et la première moitié du XVIIe siècle. Définition d'un faciès régional"5. Près d'une centaine de contextes urbains et ruraux a ainsi été étudiée permettant la mise en place d'un cadre techno-typologique utilisé depuis pour les sites de consommation que nous analysons régulièrement à l'INRAP. Ce cadre a également été employé pour le seul four de potier parisien fouillé à ce jour (première moitié du XVIe siècle). Il servira aussi pour les tessonnières du XVIe siècle mises au jour à Fosses, lors de la publication du second volet d'études sur ce très important centre artisanal francilien, dirigée par Rémy Guadaguin ${ }^{6}$ et prévue pour 2007. Avec l'accumulation d'informations, la base de données et son référentiel typologique se sont étendus chronologiquement, allant désormais du XIIe au XVIIIe siècle.

La céramique du nord de la Bourgogne

11 Nevers dans son contexte régional

12 Les récentes fouilles de l'ancienne abbaye Notre-Dame (12, rue Saint-Genest) ${ }^{7}$, dirigées par Benjamin Saint-Jean Vitus (INRAP, UMR 5594), ont mis au jour un mobilier céramique abondant et parfaitement stratifié allant du Ve siècle après J.-C. jusqu'à la fin du XVIIe siècle, date de la mise en jardin du secteur. Seul un four de faïencier situé en bordure de la rue Saint-Genest est plus tardif (fin du XVIIIe siècle). Son étude en cours $^{8}$ cherche à appréhender les circuits d'approvisionnement de l'abbaye et à mettre en évidence les liens d'ordre économique et culturel avec les régions voisines. Il s'agit également de constituer un corpus de référence pour la région nivernaise. Dans cette perspective, il est apparu nécessaire d'associer l'étude du mobilier de ce site au PCR de la vallée de la Loire moyenne (Centre-Ouest de la France) dirigé par Philippe Husi (Université de Tours, laboratoire d'archéologie, UMR 6173). En effet, la céramique retrouvée à Nevers s'intègre parfaitement au faciès céramologique des sites pris en compte dans ce PCR ${ }^{9}$, qui concerne le haut Moyen Âge jusqu'au XIIe siècle et s'inscrit dans la continuité d'un précédent travail sur les périodes postérieures ${ }^{10}$. Après la caractérisation des productions de Nevers, qui sera effectuée par le laboratoire Arc'Antique, l'objectif final est de publier les ensembles nivernais les plus significatifs sur une période comprise entre le IVe et le XIIe siècle.

Les productions céramiques de la vallée de l'Yonne

Ce projet d'études a pour dessein de fournir des bases de références pour la Bourgogne septentrionale. Il se fonde sur l'exploitation scientifique des très nombreux ensembles céramiques de la fin du Moyen Âge mis au jour dans les années 1980 dans la région et qui n'ont jamais fait l'objet de publication exhaustive ${ }^{11}$. Les moyens nécessaires à ce 
programme sont importants car il s'agit d'analyser deux fours de potiers avec leurs tessonnières et le mobilier provenant des fouilles urbaines de Sens. Un partenariat entre l'INRAP et les Musées de Sens doit être engagé pour le travail sur le mobilier. Des stages destinés aux étudiants et à toute personne intéressée par la céramique archéologique pourront être organisés.

B. Les réseaux d'échanges, les transferts culturels et techniquesDiffusion des céramiques du Beauvaisis à Paris et en Île-de-France entre le XIV ${ }^{e}$ et le XVIII ${ }^{e}$ siècle

Depuis le XIVe siècle, le Beauvaisis est second fournisseur en céramique domestique de la région Île-de-France. Mais en raison de la dispersion des collections dans tout le quart nord-ouest de la France, aucune synthèse d'ampleur n'avait encore été entreprise sur leur diffusion. À partir des quantifications opérées sur une centaine de contextes franciliens, c'est cette lacune que nous cherchons à combler ${ }^{12}$.

Diffusion et distribution de la faïence à Paris à partir du XVI ${ }^{\mathrm{e}}$ siècle

À partir de la fin du Moyen Âge, trois grandes productions de vaisselle en faïence ont été diffusées sur la place de Paris : la faïence d'origine hispanique, la faïence d'origine italique et la faïence d'origine française (Lyon, Nevers, Rouen, Paris). Il reste toutefois à mieux déterminer l'origine des approvisionnements, en particulier les productions locales qui sont encore très mal connues, et à préciser la chronologie et la sociologie des approvisionnements. Différents spécialistes devront collaborer à ce projet, en particulier Alban Horry (archéologue céramologue à l'INRAP, spécialiste de la faïence lyonnaise) et Jean Rosen (chercheur au CNRS-UMR 5594, spécialiste de la faïence nivernaise et française).

Les potiers parisiens et Bernard Palissy à Paris

Dans le cadre du programme sur Palissy mené conjointement par le Musée de la Renaissance et le Centre de Recherche et de restauration des musées de France ("Étude de la production de céramique de la Renaissance à partir du fonds des œuvres palisséennes trouvées en fouilles aux XIXe et XXe siècle sur le site des Tuileries au Louvre"), je m'occupe des relations de Bernard Palissy avec le milieu parisien ${ }^{13}$. Les problèmes de caractérisation des argiles des céramiques retrouvées sur le site des Tuileries ont déjà été abordés ${ }^{14}$, mais le travail sur le fonds d'atelier, et plus particulièrement sur les céramiques tournées est toujours en cours. Il a pour perspective la participation à la réalisation d'une exposition permanente du fonds Palissy au musée d'Écouen ainsi qu'à la publication scientifique sous la direction d'Alain Erlande-Brandenburg, Directeur du Musée national de la Renaissance.

La céramique très décorée de la fin du Moyen Âge

Un mouvement décoratif propre à la production de vaisselle en terre cuite couvre toute l'Europe du Nord-Ouest depuis le XII siècle. Cette production dite "céramique très décorée", a été fabriquée par nombre de centres potiers. Ces produits, essentiellement liés à la table et à son décorum, se distinguaient des objets ordinaires et constituaient alors des objets d'un certain luxe. Le déclin de cette production se situe, selon les pays, dans le courant du XIII ${ }^{e}$ siècle ou dans les premières décennies du XIV ${ }^{e}$ siècle. En Île-deFrance, après 150 années d'absence de céramique très décorée, globalement entre le milieu du $\mathrm{XIV}^{\mathrm{e}}$ et la fin $\mathrm{du} \mathrm{XV}^{\mathrm{e}}$ siècle, apparaissent de nouveaux produits qui s'inscrivent parfaitement dans la lignée de ces productions très décorées médiévales. Cependant, ce mouvement reste limité aux premières décennies du XVI ${ }^{\mathrm{e}}$ siècle. Bien que marginal, il est pourtant en étroite relation avec les tendances artistiques et culturelles des Flandres et de la France du Nord du XV $\mathrm{XV}^{\mathrm{e}}$ siècle, puisque des objets de 
même type y ont été retrouvés. La tenue d'un colloque international sur le sujet est envisagée pour l'horizon 2007.

II. La céramique comme élément signifiant de l'étude des sociétés médiévales :

approche culturelle et sociale

Ce volet de notre recherche constitue un axe prioritaire. Il s'agit ici de montrer les implications de l'étude de la céramique à la compréhension des phénomènes sociaux (recherche de critères de différenciation sociale...) ${ }^{15}$. Les différentes études monographiques que nous effectuons dans le cadre de notre activité à l'INRAP viennent enrichir notre réflexion. Nous avons dans les précédentes années beaucoup travaillé sur le milieu urbain (quartier du Louvre, quartier Saint-Michel, quartier Saint-Paul à Paris ${ }^{16}$ et nous continuons en essayant de caractériser la nature des différentes occupations bourgeoises, artisanales, aristocratiques. La rareté des fouilles d'habitat en milieu rural pour la période qui nous occupe fait que ce domaine est largement moins bien documenté (sites de Tremblay-en-France, Bourg-la-Reine, Mitry-Mory...).

Notre problématique actuelle privilégie deux domaines : le castral et le religieux. À ce titre, nous disposons désormais de plusieurs études de référence, encore inédites ou en cours de publication ${ }^{17}$ : châteaux de la Madeleine à Chevreuse (Yvelines), de Blandy-lèsTours (Seine-et-Marne), de Roissy-en-France (Val d'Oise), manoir de Vincennes (Val-deMarne), abbaye de Chelles (Seine-et-Marne), prieuré Saint-Sauveur de Melun (Seine-etMarne), couvent des Feuillantines (Paris), église Saint-Christophe de Cergy-Pontoise (Val d'Oise). D'autres sont en cours de réalisation, comme la ferme fortifiée de Varennes-sur-Seine (Seine-et-Marne), l'abbaye Notre-Dame de Nevers (Nièvre) ou à venir comme Saint-Nazaire d'Autun (Saône-et-Loire).

21 L'appréciation de la valeur intrinsèque du matériau céramique en fonction de la période et du milieu social n'a de sens que dans une prise en compte plus large du domaine de la culture matérielle. C'est dans cet esprit qu'avec Anne Dietrich (INRAP), paléoxylologue, nous avons organisé le colloque interdisciplinaire sur la cuisine et la table à la fin du Moyen Âge, qui s'est tenu à Sens en janvier 2004 et dont la publication est en cours ${ }^{18}$.

\section{NOTES DE FIN}

1. F. RAVOIRE, "Aperçu sur l'artisanat de la poterie de terre en Île-de-France entre le XIII et le XVII ${ }^{\mathrm{e}}$ siècle", Utilis est lapis in structura. Mélanges offerts à Léon Pressouyre, Paris, CTHS, 2000, p. 447-460, fig.

2. F. RAVOIRE, A. BOUQUILLON, "La poterie de terre Renaissance en Île-de-France (XVe-XVI siècle) : production et diffusion", Terres cuites de la Renaissance, TECHNÈ, $n^{\circ}$ 20, 2004, Paris, RMN, p. 53-60.

3. Les résultats de ces recherches seront présentés au colloque EMAC 2005 qui se tiendra à l'automne à Lyon.

4. C. BESSON, D. DERIEUX (dir.), Rapport d'activité de l'année probatoire du PCR "Cartographie de l'espace parisien", année 2004, Service régional de l'archéologie, 2005, 73 p. 
5. F. RAVOIRE, La vaisselle de terre cuite en Île de France entre la fin du XVe et la première moitié du XVII siècle Définition d'un faciès régional, Thèse de l'université Paris I, 1997, 4 volumes, 930 p. (en cours de publication).

6. R. GUADAGNin, Fosses - Vallée de l'Ysieux, Mille ans de production céramique en Île-de-France, vol. 1, Les données archéologiques et historiques, Caen, Publications du CRAHM, 2000, $367 \mathrm{p}$.

7. Voir le texte de Benjamin SAINT-JEAN VITUS dans ce volume.

8. Les ensembles du haut Moyen Âge ( $\mathrm{VII}^{\mathrm{e}}-\mathrm{X}^{\mathrm{e}}$ siècle) sont étudiés par E. Poil (INRAP) et ceux de la période tardo-antique le sont par S. Mouton (INRAP).

9. F. RAVOIRE, in P. HUSI, dir, La céramique du haut Moyen Âge de la vallée de la Loire moyenne (Centre-Ouest de la France), rapport d'activité 2004 du PCR régional H19-1996, Tours, UMR 6173 CITERES “Laboratoire Archéologie et Territoires”, Orléans : SRA Centre, INRAP, 2004.

10. P. HUSI (dir.), La céramique médiévale et moderne du Centre-Ouest de la France (XI ${ }^{e}-X V I I^{e}$ siècle). Chrono-typologie de la céramique et approvisionnement de la vallée de la Loire moyenne, Numéro spécial de la revue archéologique du Centre, Férac éd., 2003, 110 p.

11. Voir les différents articles de Didier PERRUGOT, notamment ceux du catalogue de l'exposition Bourgogne Médiévale, Dijon, 1981 et ceux du numéro spécial des Dossiers de l'archéologie.

12. Ce travail, en cours de publication, a été présenté dans trois séminaires d'archéologie médiévale (Université de Picardie en 2002, EHESS en 2003, Université de Paris I en 2004).

13. F. RAVOIRE, ibidem.

14. A. Bouquillon, J. CASTAIng, A. LeClaire, F. RAVoire, o. LeConte, "Palissy Ceramics: Elemental Analysis and Origin of Clays", Actes du colloque international EMAC 03, Lisbonne, novembre 2003 (à paraître) ; A. BOUQUILLON, O. LECONTE, "Relire Palissy à la lumière des analyses”, Terres cuites de la Renaissance, TECHNÈ n 20, 2004, Paris, RMN, p. 69-76.

15. Voir nos deux études sur le sujet : F. RAVOIRE, "Céramique et différenciation sociale : l'exemple de la vaisselle de table à la Renaissance en Île-de-France", Boire et Manger en Île-de-France. Actes des journées archéologiques d'île-de-France, Paris, 9 et 10 décembre 2000, p. 48-56 et "Céramique importée et différenciation sociale : l'exemple de la vaisselle parisienne à la Renaissance (fin du XVe- XVI ${ }^{\mathrm{e}}$ siècle)", 3rd International Conference of Medieval and Later Archaeology, Medieval Europe - Centre - Region - Periphery, Bâle Septembre 2002, p. 364-372.

16. F. RAVOIRE, “Un dépotoir du XVI ${ }^{\mathrm{e}}$ siècle à Paris", Archéologie médiévale, 1991, CNRS et F. RAVOIRE, dans P. VAN OSSEL dir, Les jardins du Carrousel, DAF n 73, Paris, 1998.

17. Voir récemment, F. RAVOIRE, "Un ensemble céramique provenant du couvent des Feuillantines à Paris, de la fin du XVII ${ }^{\mathrm{e}}$ et début XVIII ${ }^{\mathrm{e}}$ siècle", Revue archéologique de Picardie, 2004, p. 175-197 ; F. RAVOIRE, “Approvisionnement céramique en contexte monastique, l'exemple des abbayes de Chelles et du couvent de Feuillantines à Paris sous l'ancien Régime", L'approvisionnement des établissements religieux au Moyen Âge et à l'époque moderne, Actes du colloque de Lille 2003, Université de Lille, à paraître dans les cahiers du CAHMER.

18. F. RAVOIRE, A. DIETRICH, "La cuisine et la table dans la France de la fin du Moyen Âge. Colloque et exposition", in : Études et Travaux 2003-2004, CEM 8, Auxerre 2004, p. 123-129. 
INDEX

Mots-clés : céramique

Index géographique : France/Bourgogne, France/Bassin parisien 